\title{
Narrative Element or Self-expressive Element: Two Roles of Colors in Araby and Kew Garden
}

\author{
Jian Zhang ${ }^{1} \&$ Zheng-Cai $\mathrm{Li}^{1}$ \\ ${ }^{1}$ School of Foreign Languages, Dalian University of Technology, Dalian, China \\ Correspondence: Zheng-Cai Li, School of Foreign Languages, Dalian University of Technology, Dalian, China.
}

Received: July 3, 2018 Accepted: July 29, 2018 Online Published: August 22, 2018

doi:10.5539/ells.v8n3p55 URL: https://doi.org/10.5539/ells.v8n3p55

\begin{abstract}
This paper aims to compare the different applications of colors in narrative in two modern short stories, James Joyce's Araby and Virginia Woolf's Kew Garden. It has been found that two different roles of colors are presented-colors function as narrative elements and self-expressive elements. Colors and lights in Araby are subjected to narration while colors and lights in Kew Garden stand out of events and are independent from narration. It seems that Joyce employs colors and lights as symbols to implicate what he tried to express, while Woolf frees colors and lights by treating them as subjectivity. The comparison between the usages of colors in those two short stories has been conducted through two parts, colors to feel vs. colors to view, and colors with symbolic meaning and colors with natural/ordinary meaning.
\end{abstract}

Keywords: Araby, Kew Garden, color as narrative elements, color as self-expressive elements

\section{Introduction}

Color is an indispensable element in literary works since the description of matters, space and events, the expression of characters' moods, sentiments, and situations, and the foundation of narrative tones and atmosphere can't do without the help of varieties of colors and lights. Descriptive function and expressive function are two major roles colors play in traditional narrative works - to portray the appearance of a given object directly and to depict one's sentiments and sensibilities indirectly. The roles of color in literary works change along with the development and evolution of narrative styles and techniques, which is determined by the change and evolution of human experience. At the end of the $19^{\text {th }}$ century and the beginning of the $20^{\text {th }}$ century, the phenomenon that "human character changed", and "all human relations have shifted" (Woolf, 1924, p. 3) demands reforms of narrative techniques and styles; those emerging philosophies such as Henri Bergson's Intuitionism and psychological time and Freudian psychological analysis also push forward the "inward turn" in modern literary works (Hanna, 2016, p. 79) - one of the defining characteristics of the modernist narrative. Therefore, modernist works adopt new techniques like interior monologue, stream of consciousness, epiphany, and fragmentation, etc. to present the new human experience. The employment of colors in literary works also shows something new.

This paper deals with the comparisons of colors' employments in Joyce's Araby and Woolf's Kew Garden. It attempts to show that two different roles of colors are presented-colors functions as narrative elements and self-expressive elements. In Araby, colors (dark, light, brown, blind, yellow, gloomy, etc.) blend in the narrative through two aspects: one, those colors varies along with the change of the character's (the boy) sentiments and imagination; two, those colors carry different symbolic meanings with them. On the contrary, in Woolf's Kew Garden, colors (red, blue, yellow, gold, green, etc.) drop out of events and act as dependent subjects: one, those colors weave into the canvas in post-impressionist style, in which four scenes unfold in turn; two, those colors never participate in narrative and varies with the change of scenes and time sequence; three, although they have no symbolic meanings, the compatibility and harmony within those colors do serve as a foil to the coldness, desolateness and solitude among those characters.

\section{Colors to Feel vs. Colors to View}

One can feel and touch colors in Araby, while one can only view those colors in Kew Garden. Joyce employs colors for perceptional artistic effects while Woolf pursues colors' visual artistic effects.

In Araby, colors are bestowed with substantial qualities and sensation since those colors varies along with the 
change of the character's (the boy) moods, sentiments and imagination. From the boy's illusion of loving Mangan's sister at the beginning to his effort to make that illusion into reality through going to the bazaar Araby, then to the disillusion of his vanity at the end, his personality evolves from purely innocent, idealist and romantic to sophisticated, realistic and cynic, and his temperament also transforms from introversion and gentleness to "anguish and anger" (Joyce, 2004, p. 254). The implications of color change at every turn of the boy's temperament and sentiment. The setting presents a cold, dark and indifferent tone, which omens the boy's disillusion: a blind and quite street under church's oppression, two isolated and uninhabited houses at the blind end. Even boys' play could not break such somber atmosphere.

When we met in the street the houses had grown sombre. The space of sky above us was the colour of ever-changing violet ... The cold air stung us and we played till our bodies glowed... The career of our play brought us through the dark muddy lanes... to the back doors of the dark dripping gardens... (Joyce, 2004, p. 249)

The color turns to be bright, stimulating, sublime and mysterious when Mangan's sister shows up because the boy falls in love with her. When she calls her brother back, her figure is "defined by the light from the half-opened door" (Joyce, 2004, p. 250). When she speaks with the boy, her body is lit up, "the light from the lamp opposite our door caught the white curve of her neck, lit up her hair that rested there and, falling, lit up the hand upon the railing" (Joyce, 2004, p. 251). She is always accompanied by "light" like an angel in the boy's imagination. During his waiting for his uncle, he keeps think of her bright figure and the "light" around her to resist surrounding darkness and coldness. Love in imagination seems drive those darkness and misery away.

Finally, when his illusion comes to end, he realizes that he is a creature driven and derived by vanity, the darkness falls forever. "The upper part of the hall was now completely dark. Gazing up into the darkness I saw myself as a creature driven and derided by vanity; and my eyes burned with anguish and anger." (Joyce, 2004, p. 254) At last he steps out of his fantasy and comes to the epiphany that he is not a knight in a romance who could win his beloved through sacrifice and all his efforts, to pursue love and to leave such a dark and indifferent setting, go in vain.

In Kew Garden, colors are endowed with independence and subjectivity and the ability of self-expression. Colors and lights weave into the canvas (the location, Kew Garden) in a post-impressionist style, and have nothing to do with characters' personality or sentiments. They are completely free and not slaves bound to characters any more. Woolf pursues a splendid visual art by juxtaposition of expressive elements (tints and shapes) and strange images. The setting part is a grand post-impressionist painting by employing intense tints and luminous lights in various shapes to present subjective objects.

From the oval-shaped flower-bed there rose perhaps a hundred stalks spreading into heart-shaped or tongue-shaped leaves half way up and unfurling at the tip red or blue or yellow petals marked with spots of colour raised upon the surface; and from the red, blue or yellow gloom of the throat emerged a straight bar, rough with gold dust and slightly clubbed at the end. (Woolf, 2009, p. 27)

Colors and lights are independent from narration, and have nothing to do with characters' personality or sentiments, nor with their activities. "Red or blue or yellow" are basic tints that couldn't be reduced and could merge together to generate all varieties of tints. The first couple are absorbed into their memory that he is recalling his first love and she is enjoying her first kiss; the elder man in the second group is obsessed with spirits, death and heaven which might be the aftermath of war while the younger man is gazing around impatiently and pretending to listen to his murmuring; the two elder women of the lower middle class talk about nonsense; and the last young couple makes great effort to figure out what "it" is but in vain.

\section{Colors with Symbolic Meaning vs. Colors with Natural Meaning}

Tints and lights in Araby carry symbolic meaning with them which conceals their natural significance while those in Kew Garden only carry natural meaning but in a new way.

Joyce employs colors to implicate that the stifling darkness of church and religion, the decay of secular society under the oppression of religion, and the disillusion of individual salvation under the oppression of religion, society as well as family. "Darkness" is always associated with the church and its representatives (priest) - the church that controls the whole area, the Christian Brother School that restricts boys' freedom, and the ambitious priest that is zealous in public charity but preaching hint that the Christian church operates power over the whole society like a dark curtain hung down from the sky, and clergies look like secular officials since they shares great interests in public affairs, not in preaches and sermons. "Blind", "cold" and "dark" are linked to streets and houses that symbolize secular society of Dublin, which suggests that the society and secular persons like the boy's uncle and aunt are full of indifference, coldness and solitude. 
North Richmond Street, being blind, was a quiet street except at the hour when the Christian Brothers' Schoolt set the boys free. An uninhabited house of two storeys stood at the blind end, detached from its neighbours in a square ground. The other houses of the street, conscious of decent lives within them, gazed at one another with brown imperturbable faces. (Joyce, 2004, p. 249)

"Light" is always a rival force to "darkness" which implicates enlightenment, salvation and love and hope. Ironically, "light" is always from Mangan's sister - the boy's secret love and his angel, and his salvation, not from the church or any holy creatures. When she first appears, she is like a goddess since "her figure is defined by the light from the half-opened door" (Joyce, 2004, p. 250). "I" want to pursue the "light" emitted from her body every minute. Every morning, "I" hide in shadow to watch her and "I kept her brown figure always in my eye and, when we came near the point at which our ways diverged, I quickened my pace and passed her" (Joyce, 2004, p. 250). When she speaks to the boy, he is absorbed by the light.

She held one of the spikes, bowing her head towards me. The light from the lamp opposite our door caught the white curve of her neck, lit up her hair that rested there and, falling, lit up the hand upon the railing. It fell over one side of her dress and caught the white border of a petticoat, just visible as she stood at ease. (Joyce, 2004, p. 251)

Since then, her figure and the light from the white curve of her neck linger around the boy's mind. The light, her figure, even her name functions as a guide and a guard for the boy - they guide the boy to the bazaar and guide him to final epiphany. They guard him, when he is waiting his uncle impatiently from those tiresome complaints and murmuring between his aunt and the visiting woman, from the decaying society of Dublin. However, the light loses in the battle with the darkness. The boy's illusion becomes disillusion at the end. "I heard a voice call from one end of the gallery that the light was out. The upper part of the hall was now completely dark" (Joyce, 2004, p. 254).

The employment of colors and lights in Kew Garden is generally based on nature and objective matters. However, Woolf adopts colors and lights in two novel ways which bestow lifeness and subjectivity to them: one, Woolf presents the permeability of colors through the interaction between tints and lights; two, the juxtaposition of moving and still images makes those colors and lights moves vividly. It seems that those people in Kew Garden become background since they have already been assimilated by the beautiful canvas formed by colors and lights.

Woolf presents the permeability of colors through the interaction between tints and lights, which come from three origins: the multiple colored flowers and other natural matters, the rainbow sunlight, and those colorful clothes people wear. Colors and lights share high compatibility. The three basic colors, "red or blue or yellow", show up five times in the text because they are not only the natural appearance of matters, but also they could generate hundreds of other colors by emerging together. For example, blue and yellow will generate green; red and yellow will create orange; red and blue could form purple; and they can produce thousands of colors by adjustments of proportion. The repetition of "red or blue or yellow" is a signal of compatibility and harmony between colors, which reminds us that those people in Kew Garden are rarely communicating with each other. Instead, they are preoccupied with their past, wounds and nonsense. The word "stain" also presents the permeability between colors and lights. Colors and lights would stain each other, "the red, blue and yellow lights passed one over the other, staining an inch of the brown earth beneath with a spot of the most intricate color" (Woolf 12). Even the shell of the snail is stained with "red or blue or yellow".

The juxtaposition of moving and still images makes those colors and lights moves vividly. A single flower is still - "the red, blue or yellow gloom of the throat emerged a straight bar, rough with gold dust" (Woolf, 2009, p. 12) while the sea of flowers and leaves are moving when breeze comes. The raindrop is dynamic - " it expanded with such intensity of red, blue and yellow the thin walls of water that one expected them to burst and disappear" (Woolf, 2009, p. 12). The movement of sunlight is another significant image. The light moves to green leaves under which the branching threads of fiber beneath the surface are quite visible; the light "moves on and spread its illumination in the vast green spaces beneath the dome of the heart-shaped and tongue-shaped leaves" (Woolf, 2009, p. 12).

\section{Conclusion}

Colors and lights in Araby are subjected to narration, while colors and lights in Kew Garden stand out of events and are independent from narration. It seems that Joyce employs colors and lights in as symbols to implicate what he tried to express, while Woolf frees colors and lights by treating them as subjectivity.

In Araby, colors are bestowed with substantial quality and sensation since those colors varies along with the 
change of the character's (the boy) moods, sentiments and imagination. In Kew Garden, colors are endowed with independence and subjectivity and the ability of self-expression. Those colors weave into the canvas (Kew Garden) in post-impressionistic style, play their own game, and have nothing to do with characters' personality or sentiments. Joyce employs colors to implicate that the stifling darkness of church and religion, the decay of secular society under the oppression of religion, and the disillusion of individual salvation under the oppression of religion, society and family. Woolf adopts colors and lights in two novel ways which bestow lifeness and subjectivity to them: one, Woolf presents the permeability of colors through the interaction between tints and lights; two, the juxtaposition of moving and still images makes those colors and lights moves vividly.

\section{Acknowledgements}

The research is supported by "the Fundamental Research Funds for the Central Universities", Project No. DUT17RW125 and "Liaoning Social Science Planning Fund" funded by Liaoning Planning Provincial Office of Social Science, Project No. L18BWW006.

\section{References}

Hanna, J. L. (2016). Key Concepts in Modernist Literature. Shanghai: Shanghai Foreign Language Education Press.

Joyce, J. (2004). A Portait of the Artist as a Young Man and Dubliners with an Introduction and Notes by Kevin J. H. Dettmar. New York: Barnes \& Noble Classics.

Woolf, V. (1924). "Mr. Bennett and Mrs. Brown". Retrieved July 1, 2018, from http://www.columbia.edu/ em36/MrBennettAndMrsBrown.pdf

Woolf, V. (2009). A Haunted House and Other Short Stories. South Australia: University of Adelaide.

\section{Copyrights}

Copyright for this article is retained by the author, with first publication rights granted to the journal.

This is an open-access article distributed under the terms and conditions of the Creative Commons Attribution license (http://creativecommons.org/licenses/by/4.0/). 